\title{
ADAPTACIÓN FONÉTICA EN PACIENTES CON DIFERENTES APARATOS ORTODÓNCICOS
}

AUTORES: INSTITUCIÓN: PAIS:
Villanueva P., Fernández M.A., Durrals W, Vargas J., Rojas D., Álvarez E. Universidad De Chile, Facultad de Odontología, Facultad de Medicina Santiago de Chile-Chile

\section{RESUMEN}

Los pacientes con maloclusiones son sometidos a tratamientos interceptivos, ortopédico, ortodóncico y/o ortodóncico-quirúrgico, usualmente mediante aparatos removibles o fijos. Éstos pueden bloquear uno o más puntos articulatorios de distintos fonemas, por lo que los pacientes refieren dificultades de habla luego de su instalación. La presente investigación pretende determinar el efecto que producen los aparatos ortodóncicos removibles, aparatos ortodóncicos linguales y aparatos de expansión palatina rápida, en la articulación de fonemas del español Chileno. Tras obtención de consentimiento informado, se evaluaron y agruparon sujetos según: aparatos ortodóncicos removibles con referencias linguales (grupo $\mathrm{G} 1, \mathrm{n}=15$ ), aparatos ortodóncicos removibles sin referencias linguales $(G 2 n=15)$, aparatos ortodóncicos linguales $(G 3$, $\mathrm{n}=13$ ), aparatos de expansión palatina rápida ( $\mathrm{G} 4, \mathrm{n}=16$ ), aparatos linguales individualizados ( G5 $n=13$ ). Para la evaluación se utilizó un test de articulación de fonemas en cinco tiempos: a) previa instalación, b) inmediatamente post- instalación, c) 24 horas d) una semana y e) un mes después de la instalación. Los pacientes no recibieron tratamiento de habla. Se utilizó el test t-student para el análisis estadístico. Inmediatamente post-instalación los pacientes G3 mostraron la alteración del $19 \%$ de los fonemas, en comparación con el $45 \%, 46.3 \%, 53 \%$ y $52.9 \%$ obtenidos por G5, G4, G1, G2, respectivamente. Los fonemas más frecuentemente afectados para todas las técnicas fueron / d /, / s /, / t /, / n /, / rr /, / y/, / ch /. Tras 24 horas fue de 29.4\%, 52.9\%, $16.3 \%$ y $34 \%$ de los fonemas para G1, G2, G3 y G5, respectivamente. Tras 7 días los grupos mostraron $17 \%, 47 \%, 13.12 \%, 30.14 \%$ y $25 \%$. Luego de un mes, G4 mostró alterados $9.56 \%$ de los fonemas en comparación con $6.33 \%$ por G3, mientras que G5 presentó un $22 \%$ de los fonemas medios afectados. La producción de fonemas mejoró tras un mes de uso excepto para el fonema /rr/ en G3 y para los fonemas medios en G5. Pacientes con aparatos ortodóncicos con referencias linguales se adaptaron más rápidamente que con otras técnicas. Las alteraciones en la producción de fonemas no parecen ser permanentes mostrándose adaptación al uso del aparato y recuperación de la producción de los fonemas previos a la instalación.

Palabras clave: Fonética, Habla, Ortodoncia

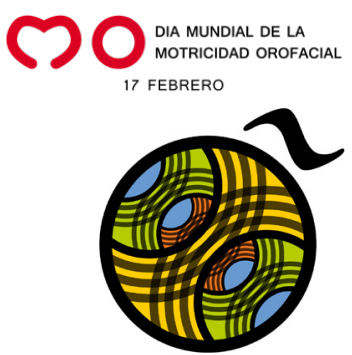

